\title{
ANALISA KELAYAKAN INVESTASI TI MENGGUNAKAN METODE COST-BENEFIT
}

\author{
Jiesianti D. Doerachman ${ }^{(1)}$,Ir.S.T.G. Kaunang,MT ${ }^{(2)}$,Stanley D.S. Karouw,ST,MTI. ${ }^{(3)}$,Yaulie D.Y. Rindengan,ST,MM,MSc. ${ }^{(4)}$

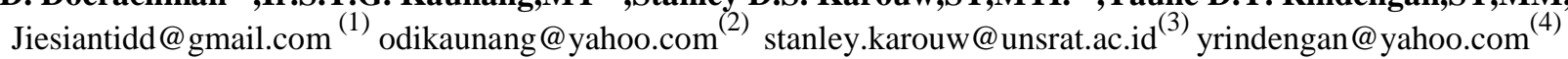

Fakultas Teknik, Universitas Sam Ratulangi Manado-95115

\begin{abstract}
Abstrak
Tujuan dari penelitian ini membahas tentang bagaimana menghitung suatu kelayakan dari investasi IT yang telah di tanamkan di sebuah perusahaan, dengan melihat apakan manfaat dari suatu investasi di perusahaan dapat meningkatkan kualitas material maupun non-material. dengan menggunakan metode Cost-Benefit. Sebelum menggunakan analisis ini kita harus mengidentifikasi tentang komponen-komponen yang ada, agar bisa kita gunakan sebagai perhitungan variable Proyek. Di dalam laporan ini juga membahas tentang kesulitan manfaat diidentifikasi dan bagaimana cara menghitungnya, manfaat terutama berwujud. Perhitungan ini di bantu dengan menggunakan Tools Aplikasi CBA yang akan digunakan sebagai Sistem Pendukung Keputusan.

Kata kunci : $\quad$ Investasi IT, Cost-Benefit, kelayakan investasi IT, Tools CBA
\end{abstract}

\section{Pendahuluan}

Di abad 21 saat ini, kata teknologi informasi merupakan kata yang sudah tidak asing lagi di dengar,banyak organisasi profit yang sangat mengandalkan teknologi sebagai alat bantu dalam menyelesaikan suatu pekerjaan. TI merupakan faktor utama yang mempengaruhi pekerjaan. Jika dilihat dari kelayakan dalam berinvestasi pengukuran yang dilakukan oleh organisasi profit yang menggunakan TI, dikarenakan biaya yang akan di gunakan tidaklah sedikit, karena biaya yang akan di keluarkan oleh organisasi begitu besar sehingga dalam pengeluaran biaya harus dipertimbangkan sebaik-baiknya. Efektifitas penggunaan TI secara umum memang sangat sulit diidentifikasi, hal ini dikarenakan pengembangan sistem informasi manajemen yang biasanya menyita banyak investasi ternyata tidak bisa memberikan kepastian pengembalian hasil yang nyata secara ekonomis. ini menyebabkan perusahaan kebingungan untuk mengambil keputusan secara efektif. hal ini lebih dikarenakan sulitnya mengukur nilai keuntungan ekonomis yang dihasilkan dari

sebuah sistem informasi manajemen karena yang dihasilkan lebih berupa peningkatan kinerja operasional perusahaan yang sifatnya intangible. Agar dapat mengantisipasi permasalahan yang terjadi diperusahaan, dilakukannya suatu perhitungan investasi agar dapat dilihat investasi yang dikeluarkan dapat memberikan keuntunggan bagi organisasi. Dengan menggunakan Metode CostBenefit Analisys di mana metode ini merupakan analisis yang digunakan untuk mengetahui besaran keuntungan atau kerugian serta kelayakan suatu proyek. Dalam perhitungannya, analisis ini memperhitungkan biaya serta manfaat yang akan diperoleh dari pelaksanaan suatu program atau proyek. Dalam analisis CBA perhitungan manfaat serta biaya ini merupakan satu kesatuan yang tidak dapat dipisahkan. Analisis ini mempunyai banyak bidang penerapan. Salah satu bidang penerapan yang umum menggunakan rasio ini adalah bidang investasi. Sesuai dengan makna teksualnya yaitu CBA( manfaat biaya) maka analisis ini mempunyai penekanan dalam perhitungan tingkat keuntungan atau kerugian suatu program atau suatu rencana dengan mempertimbangkan biaya yang akan dikeluarkan serta manfaat yang akan dicapai.

\section{Landasan Teori}

\section{A. Teknologi Informasi}

Menurut Jeffrey, Lonnie dan Kevin (2004), "teknologi informasi merupakan istilah yang menggambarkan kombinasi teknologi computer (hardware dan software) dengan teknologi komunikasi (jaringan data, gambar dan suara)".

$B$. Investasi Teknologi Informasi

Menurut Edmund W. Fitzpatrick (2005), "investasi TI adalah investasi yang terdiri dari biaya siklus hidup total keseluruhan proyek atau potongan proyek yang melibatkan TI, termasuk biaya operasional paska-proyek sistem yang diterapkan".

C. Metode Cost Benefit Analysis

Indrajit , Eko. (2010) Pada dasarnya, metode pengukuran dan analisa cost-benefit didasarkan pada cara serta perspektif manajemen dalam menilai kinerja teknologi informasi yang diimplementasikan. Terkait dengan paradigma ini, setiap metodelogi yang dipilih dan dipergunakan oleh manajemen memiliki karakteristik khusus - yang 
membedakannya dengan metodologi lain.Cost Benefit Analysis Framework ini dapat dilihat pada Gambar 1.

\section{Analisis Kelayakan}

Menurut Indrarajit, Eko (2010) Salah satu tantangan terbesar dalam menilai kelayakan sebuah investasi pembangunan teknologi informasi adalah menilai atau memperkirakan manfaat apa yang akan diperoleh oleh perusahaan nantinya. Dikatakan sebagai tantangan karena kebanyakan manfaat yang diberikan oleh teknologi informasi bersifat intangible atau sulit dikuantifikasikan ke dalam satuan angka finansial dan tidak secara langsung berpengaruh terhadap profitabilitas perusahaan.

Studi kelayakan bisnis akan menyangkut tiga aspek yaitu, aspek manfaat ekonomis bagi usaha itu sendiri, aspek manfaat ekonomis usaha tersebut bagi Negara tempat usaha tersebut dilaksanakan, dan aspek manfaat social usaha tersebut.

Alat Analisis

alam menjalankan usaha pada umumnya menggunakan metode-metode penilaian investasi yang diantaranya adalah dengan menggunakan metode:

1. Payback Period

2. Net Present Value

3. Internal Rate of Return

4. Return on Investment

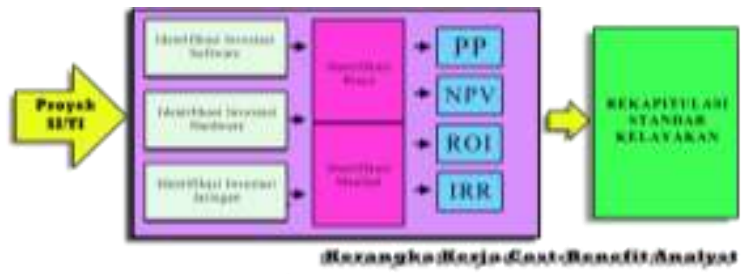

Gambar 1. Cost Benefit Analysis Framework (Sumber : Indrarajit, Eko, 2010)

\section{Metodologi Penelitian}

\section{A. Tempat Dan Waktu Penelitian}

Dalam pelaksanaan tugas akhir ini penulis mengambil tempat penelitian pada organisasi profit yang ada dimanado yaitu IT Center Manado, Ruang Laboratorium Sistem Komputer (LSK), Jurusan Teknik Elektro, Perpustakaan Fakultas Teknik Universitas Sam Ratulangi (UNSRAT), dan rumah penulis. Waktu penelitian direncanakan berlangsung selama 4 bulan, yaitu dari tanggal 15Mei 2012- 15 September 2012.

\section{B. Peralatan}

Untuk melakukan perhitungan menggunakan alat tulis menulis, laptop, printer, kamera digital,kalkulator, serta jaringan internet.

Dalam mengerjakan tugas akhir ini mulai mengobservasi dilapangan, wawancara, dan studi pustaka Secara lebih spesifik perlengkapan komputer beserta pendukung yang digunakan yaitu: 1. Spesifikasi Komputer
a. Sistem Operasi: Windows 7
b. Processor Intel Core i5-480M 2.70Ghz
c. Memory RAM 2GB DDR2
d. Harddisk 500Gb HDD

2. Aplikasi - aplikasi yang dipakai :

a. Java Development Kit (JDK) Ver.7

C. Prosedur Penelitian

Prosedur yang dilakukan dalam menghitung investasi TI menggunakan metode cost benefit sebagai berikut:

1. Sebelum melakukan penelitian, penulis terlebih dahulu melakukan studi literatur. Penulis mencari materi-materi yang berhubungan dengan perhitungan investasi TI dan metode cost benefit.

2. Setelah mendapatkan informasi yang dibutuhkan, maka penulis mencari programprogram pendukung dalam pembuatan tugas akhir kemudian melakukan penginstallan.

3. Setelah itu penulis merancang tampilan dari aplikasi yang akan dibuat serta menginput datadata dalam database yang nanti akan digunakan pada aplikasi.

4. Penulis menggunakan Java Development Kit (JDK) Ver.7 untuk membangun aplikasi perhitungan investasi TI menggunakan metode cost benefit.

5. Penulis menguji aplikasi untuk mengetahui kesalahan yang mungkin terjadi atau kekurangan dari aplikasi.

\section{HASIL DAN PEMBAHASAN}

\section{A. Perhitungan Awal Sistem}

Tahapan selanjutnya adalah menghitung investasi dengan metode yang sudah dipilih yaitu metode cost benefit.

1. Biaya pengadaan (procurement cost)

Meliputi semua pengeluaran biaya pengadaan, yang berkaitan dalam proyek investasi. Dapat dilihat di tabel 1.

2. Biaya Persiapan Operasional (Start Up Cost) Biaya yang di siapkan untuk pengoperasian proyek yang dilaksanakan. Dapat dilihat di tabel 2.

3. Biaya Proyek (Project Related Cost)

Berkait dengan biaya yang akan di jalankan termasuk biaya penerapan. Dapat dilihat di tabel 3 .

4. Biaya Operasional (ongoing cost)

Meliputi semua biaya operasian dan perawatan system. Dapat dilihat di tabel 4.

5. Manfaat Keuntungan Yang Berwujud (Tangible Benefits)

Manfaat yang berwujud yang di dapatkan dalam penghematan-penghematan yang dilakukan oleh sebuah perusahaan yang sangat menguntungkan. Dapat dilihat di tabel 5.

6. Manfaat Keuntungan Yang Tidak Berwujud (Intangible Benefits) 
Manfaat yang tidak berwujud dapat di kepuasan pengguna. Dapat dilihat di tabel 6 .

TABEL 1. BIAYA PENGADAAN (PROCUREMENT COST)
\begin{tabular}{|ll|l|}
\hline Procurement cost & \\
\hline & Biaya konsultasi & $\mathrm{Rp}$ \\
a. & pengadaan hardware & $6,000,000.00$ \\
\hline & & $\mathrm{Rp}$ \\
b. $\quad$ Biaya pembelian hardware & $208,465,900.00$ \\
\hline & Biaya instalasi hardware & $\mathrm{Rp}$ \\
c. & $6,000,000.00$ \\
\hline & Biaya fasilitas hardware & $63,150,000.00$ \\
d. $\quad$ Biaya manajemen dan & $\mathrm{Rp}$ \\
\hline & SDM & $20,750,000.00$ \\
\hline & $\mathrm{Rp}$ \\
\hline & Total procurement cost & $304,365,900.00$ \\
\hline
\end{tabular}

TABEL 2. BIAYA PERSIAPAN OPERASIONAL (START UP COST)

\begin{tabular}{|ll|ll|}
\hline Start Up Cost & & & \\
\hline & $\begin{array}{l}\text { Biaya } \\
\text { pembelian } \\
\text { software }\end{array}$ & $\mathrm{Rp}$ & $22,859,379.00$ \\
\hline & $\begin{array}{l}\text { Biaya } \\
\text { instalasi } \\
\text { networking }\end{array}$ & $\mathrm{Rp}$ & $2,500,000.00$ \\
\hline b. & $\begin{array}{l}\text { Biaya } \\
\text { manajemen } \\
\text { dan SDM }\end{array}$ & $\mathrm{Rp}$ & $20,750,000.00$ \\
\hline c & $\begin{array}{l}\text { Total start } \\
\text { up cost }\end{array}$ & $\mathrm{Rp}$ & $25,359,379.00$ \\
\hline & & & \\
\hline
\end{tabular}

TABEL 3. BIAYA PROYEK (PROJECT RELATED COST)

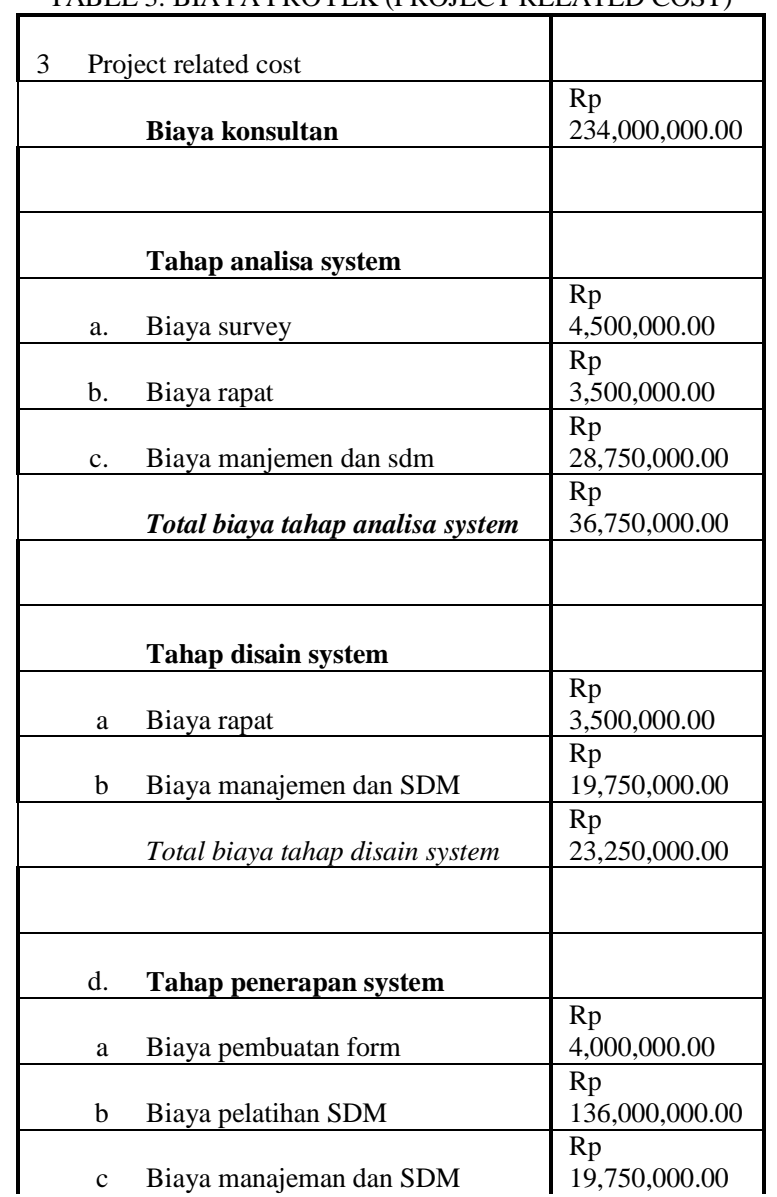

\begin{tabular}{|l|l|}
\hline & $\mathrm{Rp}$ \\
\hline total biaya pengembangan system & $159,750,000.00$ \\
\hline & $\mathrm{Rp}$ \\
\hline & $783,475,279.00$ \\
\hline
\end{tabular}

TABEL 4. BIAYA OPERASIONAL (ONGOING COST)

\begin{tabular}{|c|c|c|c|c|c|}
\hline Ongoing cost & 0 & 1 & 2 & 3 & 4 \\
\hline Biaya SDM & $\mathrm{Rp}$ & $\begin{array}{l}\mathrm{Rp}_{6^{*}} \\
84,{ }^{*}\end{array}$ & $\begin{array}{c}\mathrm{Rp} \\
886^{6^{*}}\end{array}$ & $\mathrm{Rp}_{92,4^{6^{*}}}$ & $\begin{array}{c}\mathrm{Rp}_{96}^{6^{*}} \\
\end{array}$ \\
\hline $\begin{array}{c}\text { Biaya } \\
\text { overhead }\end{array}$ & Rp & $\begin{array}{l}\mathrm{Rp} \\
252,6^{6^{*}}\end{array}$ & $\begin{array}{c}\mathrm{Rp} \\
264,^{6^{*}}\end{array}$ & $\begin{array}{l}\mathrm{Rp} \\
277,2^{6^{*}}\end{array}$ & $\begin{array}{c}\mathrm{Rp} \\
289,8^{6 *}\end{array}$ \\
\hline $\begin{array}{l}\text { Biaya } \\
\text { perawatan } \\
\text { hardware }\end{array}$ & $\mathrm{Rp}$ & $\begin{array}{c}\mathrm{Rp} \\
20,^{6^{*}}\end{array}$ & $\begin{array}{c}\mathrm{Rp}_{2} \\
216^{6^{*}}\end{array}$ & $\begin{array}{c}\mathrm{Rp} \\
226^{6^{*}}\end{array}$ & $\begin{array}{c}\mathrm{Rp} \\
23,6^{6^{*}}\end{array}$ \\
\hline $\begin{array}{l}\text { Biaya } \\
\text { perawatan } \\
\text { software }\end{array}$ & Rp & $\begin{array}{l}\mathrm{Rp} \\
206^{6^{*}}\end{array}$ & $\begin{array}{c}\mathrm{Rp} \\
200^{6^{*}}\end{array}$ & $\begin{array}{c}\mathrm{Rp} \\
206^{6^{*}}\end{array}$ & $\begin{array}{c}\mathrm{Rp} \\
206^{6^{*}}\end{array}$ \\
\hline $\begin{array}{l}\text { Biaya } \\
\text { perawatan } \\
\text { perlengkapan } \\
\text { \& fasilitas }\end{array}$ & Rp & $\begin{array}{l}\mathrm{Rp} \\
6^{6^{*}}\end{array}$ & $\begin{array}{l}\mathrm{Rp} \\
6^{6^{*}}\end{array}$ & $\begin{array}{l}\mathrm{Rp} \\
6^{6^{*}}\end{array}$ & $\begin{array}{l}\mathrm{Rp} \\
6^{6^{*}}\end{array}$ \\
\hline $\begin{array}{l}\text { Biaya } \\
\text { manajemen } \\
\text { operasional } \\
\text { system }\end{array}$ & Rp & $\begin{array}{l}\mathrm{Rp} \\
120,^{6^{*}}\end{array}$ & $\begin{array}{l}\mathrm{Rp} \\
126,^{6^{*}}\end{array}$ & $\begin{array}{l}\mathrm{Rp} \\
132{ }^{6^{*}}\end{array}$ & $\mathrm{Rp}_{138{ }^{6^{*}}}$ \\
\hline $\begin{array}{l}\text { Total biaya } \\
\text { tahap analisa } \\
\text { system }\end{array}$ & $\begin{array}{l}R p \\
783,475, \\
279.00\end{array}$ & $\begin{array}{l}\mathrm{Rp} \\
502,{ }^{6^{*}}\end{array}$ & $\begin{array}{l}\mathrm{Rp} \\
525,8^{6^{*}}\end{array}$ & $\begin{array}{l}\mathrm{Rp} \\
549,6^{5^{*}}\end{array}$ & $\begin{array}{l}\mathrm{Rp} \\
573,4^{5^{*}}\end{array}$ \\
\hline
\end{tabular}

TABEL 5. MANFAAT KEUNTUNGAN YANG BERWUJUD (TANGIBLE BENEFITS)

\begin{tabular}{|c|c|c|c|c|c|}
\hline BENEFITS & 0 & 1 & 2 & 3 & 4 \\
\hline \multicolumn{6}{|l|}{$\begin{array}{l}\text { Tangible } \\
\text { benefits }\end{array}$} \\
\hline $\begin{array}{l}\text { Efisiensi } \\
\text { biaya } \\
\text { operasion } \\
\text { al } \\
\end{array}$ & $\begin{array}{l}\mathrm{R} \\
\mathrm{p} \\
- \\
\end{array}$ & $\begin{array}{c}\mathrm{Rp}_{6^{*}} \\
42,^{6^{*}}\end{array}$ & $\begin{array}{c}\mathrm{Rp}_{6 *} \\
42,6^{*}\end{array}$ & $\begin{array}{c}\mathrm{Rp}_{6^{*}} \\
42,,^{-}\end{array}$ & $\begin{array}{c}\mathrm{Rp}_{6 *} \\
42,{ }^{6 *}\end{array}$ \\
\hline $\begin{array}{l}\text { Efisiensi } \\
\text { biaya } \\
\text { telekomun } \\
\text { ikasi }\end{array}$ & $\begin{array}{l}\mathrm{R} \\
\mathrm{p} \\
-\end{array}$ & $\operatorname{Rp}_{43,2^{5}}$ & $\begin{array}{c}\mathrm{Rp}_{43,2^{5^{*}}} \\
\end{array}$ & $\mathrm{Rp}_{43,2^{5^{*}}}$ & $\mathrm{Rp}_{43,2^{5}}$ \\
\hline $\begin{array}{l}\text { Efisiensi } \\
\text { kesalahan } \\
\text { proses }\end{array}$ & $\begin{array}{l}\mathrm{R} \\
\mathrm{p} \\
-\end{array}$ & $\begin{array}{c}\mathrm{Rp}_{6^{*}} \\
12,{ }^{*}\end{array}$ & $\begin{array}{c}\mathrm{Rp}_{6^{*}} \\
12,{ }^{6}\end{array}$ & $\mathrm{Rp}_{12,6^{*}}$ & $\begin{array}{c}\mathrm{Rp} \\
12, \text {, }^{*}\end{array}$ \\
\hline $\begin{array}{l}\text { Peningkat } \\
\text { an } \\
\text { penyewaa } \\
n\end{array}$ & $\begin{array}{l}\mathrm{R} \\
\mathrm{p} \\
- \\
\end{array}$ & $\begin{array}{c}\mathrm{Rp} \\
243 \\
6^{*}\end{array}$ & $\operatorname{Rp}_{303,75^{4^{*}}}$ & $\operatorname{Rp}_{364,5^{5}}$ & $\begin{array}{c}\mathrm{Rp} \\
425,2 \\
5^{5^{*}} \\
\end{array}$ \\
\hline $\begin{array}{l}\text { Efisiensi } \\
\text { biaya } \\
\text { persediaa } \\
\mathrm{n}\end{array}$ & $\begin{array}{l}\mathrm{R} \\
\mathrm{p} \\
- \\
\end{array}$ & $\begin{array}{l}\mathrm{Rp} \\
372, \\
6^{*}\end{array}$ & $\mathrm{Rp}_{372,6^{*}}$ & $\begin{array}{c}\mathrm{Rp} \\
372,{ }^{6^{*}}\end{array}$ & $\begin{array}{c}\mathrm{Rp} \\
372, \\
6^{*}\end{array}$ \\
\hline $\begin{array}{l}\text { Total } \\
\text { tangible } \\
\text { benefit }\end{array}$ & $\begin{array}{l}\mathrm{R} \\
\mathrm{p} \\
-\end{array}$ & $\begin{array}{c}R p \\
712,2 \\
5^{*}\end{array}$ & $\begin{array}{c}R p \\
772,95^{5^{*}}\end{array}$ & $\begin{array}{c}R p \\
833,7^{5}\end{array}$ & $\begin{array}{c}R p \\
894,4 \\
5^{5^{*}}\end{array}$ \\
\hline
\end{tabular}

TABEL 6. MANFAAT KEUNTUNGAN YANG TIDAK BERWUJUD (INTANGIBLE BENEFITS

\begin{tabular}{|c|c|c|c|c|c|}
\hline $\begin{array}{l}\text { Intangible } \\
\text { benefits }\end{array}$ & 0 & 1 & 2 & 3 & 4 \\
\hline $\begin{array}{l}\text { Peningka } \\
\text { tan }\end{array}$ & $\mathrm{R}$ & & & & \\
pelayana & $\mathrm{p}$ & $\mathrm{Rp}$ & $\mathrm{Rp}$ & $\mathrm{Rp}$ & $\mathrm{Rp}$ \\
n & - & $6^{7 *}$ & $75,^{6^{*}}$ & $906^{6^{*}}$ & $105,6^{6^{*}}$ \\
\hline Pingkata & & & & & \\
n kinerja & $\mathrm{R}$ & & & & \\
SDM & $\mathrm{p}$ & $\mathrm{Rp}$ & $\mathrm{Rp}$ & $\mathrm{Rp}$ & $\mathrm{Rp}$ \\
& - & $48,6^{6^{*}}$ & $6^{7 *}$ & $72,^{6^{*}}$ & $84,6^{6^{*}}$ \\
\hline
\end{tabular}




\begin{tabular}{|c|c|c|c|c|c|}
\hline $\begin{array}{l}\text { Peningka } \\
\text { tan } \\
\text { keputusa } \\
\mathrm{n} \\
\text { manager }\end{array}$ & $\begin{array}{l}R \\
p \\
-\end{array}$ & $\begin{array}{l}\mathrm{Rp} \\
72,{ }^{6^{*}}\end{array}$ & $9^{\mathrm{Rp}}$ & $\begin{array}{l}\mathrm{Rp} \\
108,{ }^{6^{*}}\end{array}$ & $\begin{array}{l}\mathrm{Rp} \\
126,{ }^{6^{*}}\end{array}$ \\
\hline $\begin{array}{l}\text { Total } \\
\text { intangibl } \\
e \\
\text { benefits }\end{array}$ & $\begin{array}{l}R \\
p\end{array}$ & $\begin{array}{l}R p \\
18^{7^{*}}\end{array}$ & $\begin{array}{c}R p \\
225,{ }^{6^{*}}\end{array}$ & $\begin{array}{l}R p \\
270,{ }^{6^{*}}\end{array}$ & $\begin{array}{c}R p \\
315,{ }^{6^{*}}\end{array}$ \\
\hline $\begin{array}{l}\text { Total } \\
\text { Benefits }\end{array}$ & $\begin{array}{l}\mathrm{R} \\
\mathrm{p} \\
-\end{array}$ & $\begin{array}{c}\boldsymbol{R} \boldsymbol{p} \\
892,2^{6}\end{array}$ & $\begin{array}{l}\boldsymbol{R p} \\
997,95^{4^{*}}\end{array}$ & $\begin{array}{l}R p \\
1,103, \\
7^{5 *}\end{array}$ & $\begin{array}{l}R p \\
1,209, \\
45^{5^{*}}\end{array}$ \\
\hline
\end{tabular}

\section{B. Hasil Perhitungan Alat Analisis}

1. Net Present Value (NPV).

Metode ini nilai membandingkan keseluruhan pengeluaran dengan kesuluruhan pernerimaan pada tingkat bunga tertentu. Investasi yang di lakukan di kenakan $10 \%$. maka perhitungannya adalah:

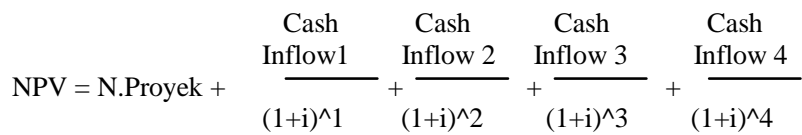

$$
\begin{aligned}
& =\mathrm{Rp}-783,475,279.00+\frac{390.200 .000}{1.1}+\frac{472.150 .000}{1.21}+\frac{554.100 .000}{1.331}+\frac{636.050 .000}{1.4641}
\end{aligned}
$$

$$
=\quad \text { Rp }-783,475,279.00+354.727 .727 .73+390.206 .611 .57+416.303 .531 .18
$$
$+434.430 .708 .28$

$=\mathrm{Rp} 783,475,279.00+\mathrm{Rp} 1,595,668,123.76$

$=\operatorname{Rn} 812.192 .844 .76$

Dari perhitungan diatas, menghasilkan NPV > 0 atau positif sebesar Rp812,192,844.76 , berarti usulan proyek dapat diterima.

2. Payback Period Method

Metode ini menghitung berapa cepat investasi yang dilakukan dalam setiap periode. Karena itu hasil perhitungannya dinyatakan dalam sutuan waktu. Jangka waktu minimum pengembalian investasi telah ditetapkan perusahan adalah tahun. Adapun perhitungan payback period sebagai berikut:

$$
\mathrm{Pp} \quad=\frac{\text { Jumlah investasi }}{\text { Kas Masuk Bersih }} \mathrm{X} \quad 12 \text { bulan }
$$

$\begin{array}{ll}\text { Inventasi } & =\operatorname{Rp} 783,475,279.00 \\ \text { Laba tahun 1 } & =\text { Rp390,200,000.00 } \\ \text { sisa inventasi } & =\operatorname{Rp} 393,275,279.00\end{array}$

Sisa investasi tahun 2 sebesar Rp393,275,279. , tertutup oleh cash inflow tahun ke 2 sebesar Rp Rp472,150,000 yaitu Rp393,275,279/ $\mathrm{Rp} 472,150,000=0.832946$

$\mathrm{Pp}$

$$
=\frac{\text { Jumlah investasi }}{\text { Kas MasukBersih }} \times 12 \text { bulan }
$$

$\mathrm{Pp}$

$$
=\frac{\mathrm{Rp} 393,275,279}{\mathrm{Rp} 472,150,000} \times \quad 12 \text { bulan }
$$$$
\mathrm{pp}=\begin{array}{llll}
0.832946 & \mathrm{X} & 12
\end{array}
$$

$$
\mathrm{PP}=\quad 9.9953
$$

Dari perhitungan diatas diperoleh hasil dengan waktu 1 tahun 9.9953bulan, ( ini lebih cepat dari perkiraan yang di tetapkan, yaitu 5 tahun). Maka dapat disimpulkan bahwa usulan proyek investasi ini layak dilaksanakan.

3. Return On Investment (ROI)

Metode ini dimana metode pengembalian investasi digunakan untuk mengukur prosentase manfaat yang dihasilkan oleh suatu proyek dibandingkan dengan biaya yang dikeluarkanya.

Cara perhitungan di gunakan dengan rumus :

$$
\begin{aligned}
\text { ROI } & =\frac{\text { Total Manfaat- Total Biaya }}{\text { Total biaya }} \\
\text { ROI } & =\frac{\operatorname{Rp~4,203,300,000-Rp~2,934,275,279.00~}}{2,934,275,279.00} \\
& =\frac{\operatorname{Rp~} 1,269,024,721.00}{\operatorname{Rp~} 2,934,275,279.00} \\
& =0.432483186 \times 100 \% \\
& =43.24 \%
\end{aligned}
$$

Pada proyek ini ROI nya adalah 0.4324 atau $43.24 \%$, ini berarti proyek ini dapat diterima, karena proyek ini akan memberikan keuntungan sebesar $43.24 \%$ dari total biaya investasinya.

4. Return On Investment (IRR)

Untuk mencari i yang tepat maka dilakukan beberapa percobaan dan perkiraan.

$\mathrm{i}=47 \%$

investasi awal $(\mathrm{Cf})=\mathrm{Rp} 783,475,279$

$$
\mathrm{r}=\mathrm{P} 1-\mathrm{C} 1
$$

$r=47 \%-11,113,884.95$

$48 \%-47 \%$

$-778.673 .67-11.113 .884 .95$

$1 \%$

$r=47 \%-11,113,884.95$

$-11.892 .558 .62$ 
$\mathrm{r}=47 \%+0.705$

$\mathrm{r}=47.70 \%$

\section{Gambaran Proyek TI Kedepan}

To-goROI

Metode ini menghitung kelayakan investasi yang akan datang,dan meramalkan suatu investasi yang akan datang sebelum di jalakan. Cara perhitungan digunakan dengan rumus :

$$
\begin{aligned}
\text { To-goROI } & =\frac{\mathrm{NPV}_{\text {today }}}{\text { Biaya pengadaan }} \\
& =\frac{\mathbf{3 2 5 , 8 8 5 , 5 3 6 . 7 9}}{161,075,900.00} \\
& =2.023^{2}
\end{aligned}
$$

Investasi Proyek yang akan datang bisa di lakukan karena dengan hasil yang di hitung dengan menggunakan to-goROI memperoleh suatu nilai yang cukup baik dalam proyek yang akan diterapkan.

Memprediksikan proyek untuk 5 tahun kedepan.

Untuk memprediksikan proyek 5 tahun kedepan sangatlah penting untuk perusahaan di karenakan agar pada saat perusahaan ingin melanjutkan pengembangan proyek dapat melihat acuan dari hasil to-goROI dengan menggunakan suku bunga bank.

Diketahui :

$$
\mathrm{i}=\text { suku bunga }(\%)
$$$$
\mathrm{f}=\text { to-goROI }(\%)
$$

$\operatorname{Tr}=$ periode kala ulang (tahun)

$\mathrm{X}_{\mathrm{Tr}}=$ persentasi invetasi proyek

untuk $\operatorname{Tr}(\%)$

Rumus :

$$
\begin{aligned}
& \mathrm{X}_{\mathrm{Tr}-1}=\mathrm{i}+(\mathrm{f} . \operatorname{Tr}) \\
& \mathrm{X}_{\mathrm{Tr}} \quad-1=\mathrm{i}+(\mathrm{f} . \mathrm{Tr}) \\
& =6 \%+\left(2.023 x \frac{1}{200}\right) \\
& =6 \%+(2.023 \times 0.01) \\
& =6.02023 \% \\
& \mathrm{X}_{\mathrm{Tr}} \quad-{ }_{-1}=\mathrm{i}+(\mathrm{f} . \mathrm{Tr}) \\
& =6 \%+\left(2.023 \times \frac{z}{200}\right) \\
& =6 \%+(2.023 \times 0.02) \\
& =6.04046 \% \\
& \mathrm{X}_{\mathrm{Tr}-1}=\mathrm{i}+(\mathrm{f} . \mathrm{Tr}) \\
& =6 \%+\left(2.023 \times \frac{I}{200}\right) \\
& =6 \%+(2.023 \times 0.03) \\
& =6.06069 \% \\
& \mathrm{X}_{\mathrm{Tr}-1}=\mathrm{i}+(\mathrm{f} . \mathrm{Tr}) \\
& \left.=6 \%+2.023 \times \frac{4}{200}\right) \\
& =6 \%+(2.023 \times 0.04) \\
& =6.08092 \% \\
& \mathrm{X}_{\mathrm{Tr}-1}=\mathrm{i}+(\mathrm{f} . \mathrm{Tr}) \\
& =6 \%+\left(2.023 \times \frac{5}{200}\right) \\
& =6 \%+(\mathrm{x} 0.05) \\
& =6.10115 \%
\end{aligned}
$$

Setelah melakukan perhitungan, kita bisa melihat presentasi proyek yang akan di kembangkan selama 5 tahun kemudian. Hasilnya layak dalam mengembangkan proyek tersebut. Dapat dilihat di gambar 2.

D. Cost Benefit Tools

Cost Benefit Tools berikut ini adalah tools yang dirancang untuk membantu dalam menghitung tiap nilai yang didapat dengan menggunakan metode Cost Benefit. Aplikasi ini dibuat dengan tujuan untuk mempercepat proses perhitungan.

Aplikasi ini dibuat dengan menggunakan bahasa pemrograman Java, dan dirancang dengan menggunakan NetBeans, salah satu IDE (IntegratedDevelopment Environment) yang mensupport penggunaan Java. Untuk dapat menjalankan aplikasi ini, diperlukan program Java Development Kit (JDK) Ver.7 (minimal).

Gambar 2 adalah grafik dari hasil presentasi proyek yang akan datang.

Gambar 3 adalah tampilan dari aplikasi cost benefit analysis tab Payback Period Method (PP), Net Present Value Method (NPV), dan Return O Invesment Method (ROI)

Gambar 4adalah tampilan dari perhitungan Payback Period Method (PP).

Gambar 5adalah tampilan dari perhitungan Net Present Value Method (NPV),

Gambar 6 adalah tampilan dari perhitungan Return Of Invesment Method (ROI)

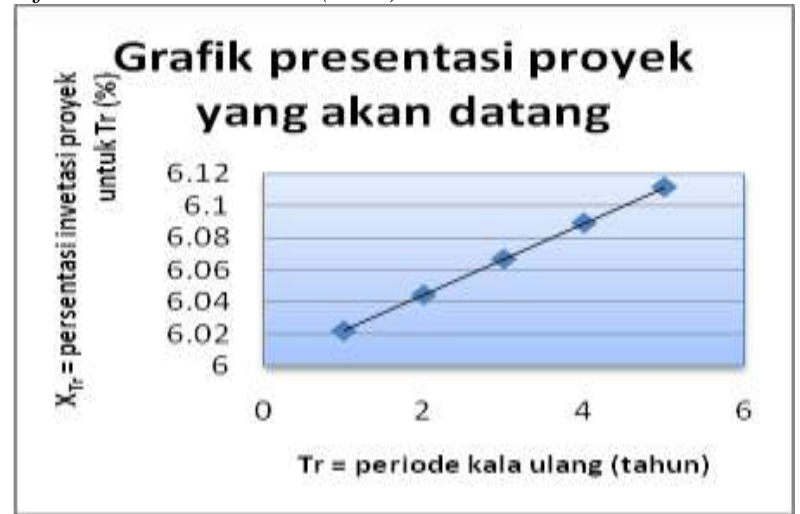

Gambar 2. Grafik Presentasi Proyek yang akan datang

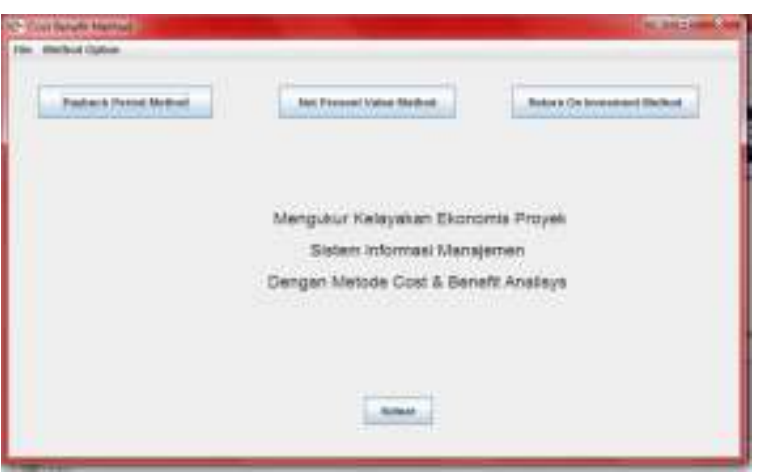

Gambar 3 Tampilan dari Cost Benefit Tools 


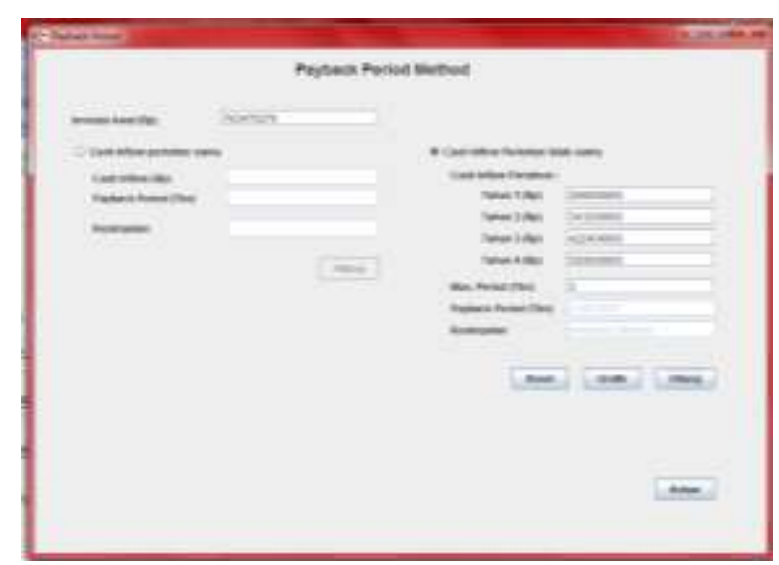

Gambar 4.Payback Period Method

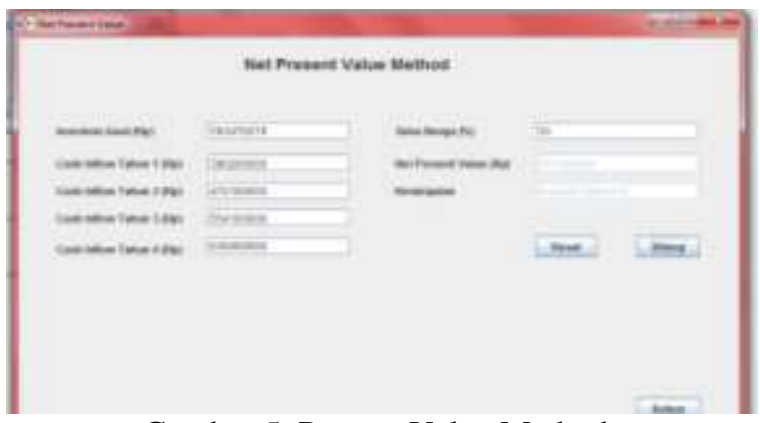

Gambar 5. Present Value Method

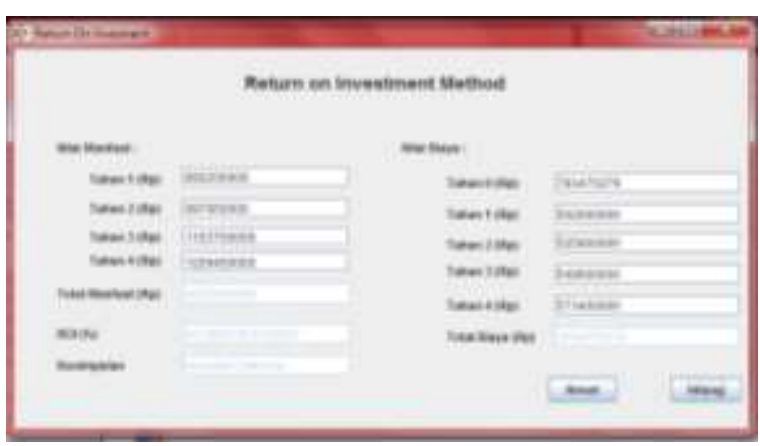

Gambar 6.Return on Investment Method

\section{Kesimpulan}

Dari pengujian yang dilakukan pada perhitungan yang telah dilakukan, maka dapat menarik kesimpulan yaitu:

1. Hasil yang didapatkan setelah menghitung menggunakan Metode CBA tersebut mendapatkan hasil sebagai berikut: NPV yang didapatkan berjumlah 812,192,844.76 , PP yang didapatkan 1 tahun 9.9953bulan, ROI yang didapatkan $43.24 \%$, dan IRR yang didapatkan $47.70 \%$. Dari hasil yang didapatkan maka proyek yang telah dikembangkan dikatakan layak karena proyek ini dapat menguntungkan pada organisasi tersebut.

2. Hasil yang didapatkan setelah menghitung menggunakan Metode CBA untuk proyek yang akan datang mendapatkan hasil $6.02023 \%$ s/d $6.10115 \%$. Dengan hasil ini maka proyek yang akan dikembangkan dikatakan layak.

3. Penggunaan metode Cost Benefit dalam mengukur biaya dan manfaat suatu proyek TI, memberikan kesempatan pada mahasiswa dalam berhubungan langsung di dunia nyata, dalam mempraktekkan dilapangan.

4. Berdasarkan hasil yang didapatkan dengan menggunakan metode cost benefit ini, diketahui bahwa proyek yang dihitung sangatlah layak di kembangkan karena dalam perhitungan proyek yang belum mendapatkan hasil sebagai berikut: diimplementasikan ini begitu sangat layak dikembangkan, namun dalam beberapa jangka waktu keuntungan yang didapatkan begitu sangat kecil, tapi jika dilakukan dengan sebaiknya maka mungkin bisa memperoleh keuntungan yang sangat besar.

\section{DAFTAR PUSTAKA}

[1] G. Prabantoro, Mengukur Kelayakan Ekonomis Proyek Sistem Informasi Manajemen Menggunakan Metode 'Cost \& Benefits Analysis' Dan Aplikasinya Dengan MS EXCEL 2000. Jakarta. 2010

[2] E. Indrajit, Kajian Strategis Analisa CostBenefit Invstasi Teknologi Informasi. Jakarta. 2010

[3] A.Dennis, Systems Analysis and Design with UML Version 2.0 An Object-Oriented Approach. Indiana University. 2005.

[4] M. Cantor, Calculate your return on investment forsoftware and systems, IBM. 2012

[5] V.C. Brown, D.W. DeHayes , J.A. Hoffer , E.W. Martin, dan W.C. Perkins, Managing Information Technology. 2012.

[6] L.W. Jeffrey dan D.B. Lonnie, System Analysis and Design Method. 2004

[7] W.F. Edmund, Planning and Implementing IT Portfolio Management: Maximizing the Return on Information Technology Investments. 2005.

[8] J.S. Marc, L.H. Jamie, M.S. Ashlyn, Information Technology Investment: DecisionMaking Methodology.2004.

[9] B. Ranti. Managing IT Investment, University of Indonesia. 2001. 